\title{
Correction to: The neuroprotective effects of stimulation of NMDA receptors against POX-induced neurotoxicity in hippocampal cultured neurons; a morphometric study
}

\author{
Farideh Bahrami ${ }^{1,2} \cdot$ Zahra Bahari $^{2} \cdot$ Reyhaneh Abolghasemi $^{3} \cdot$ Lida Golmanesh $^{1} \cdot$ Gholam Hossein Meftahi $^{1}$
}

Accepted: 16 September 2020 / Published online: 6 October 2020

(c) The Korean Society of Toxicogenomics and Toxicoproteomics 2020

Correction to: Molecular \& Cellular Toxicology

https://doi.org/10.1007/s13273-020-00091-9

Due to an unfortunate oversight, one of the author names has

been given erroneously.

It should be read: Reyhaneh Abolghasemi.

The authors apologise this mistake.

The original article can be found online at https://doi.org/10.1007/ s13273-020-00091-9.

Farideh Bahrami

faridehbahrami@protonmail.com; f.bahrami@bmsu.ac.ir

1 Neuroscience Research Center, Baqiyatallah University of Medical Sciences, Tehran, Iran

2 Department of Physiology and Medical Physics, Faculty of Medicine, Baqiyatallah University of Medical Sciences, Tehran, Iran

3 Department of Community Medicine, Faculty of Medicine, Baqiyatallah University of Medical Sciences, Tehran, Iran 